\title{
Decentralized Screening: Coordination Failure, Multiple Equilibria and Cycles
}

\author{
Thomas Gehrig \\ University of Freiburg and CEPR, London \\ and \\ Rune Stenbacka
}

Swedish School of Economics, Helsinki, HECER and Göteborg University

Discussion Paper No. 190

October 2007

ISSN 1795-0562

HECER - Helsinki Center of Economic Research, P.O. Box 17 (Arkadiankatu 7), FI-00014 University of Helsinki, FINLAND, Tel +358-9-191-28780, Fax +358-9-191-28781,

E-mail info-hecer@helsinki.fi, Internet www.hecer.fi 


\title{
Decentralized Screening: Coordination Failure, Multiple Equilibria and Cycles*
}

\begin{abstract}
We explore the inter-temporal effects of the pool externalities caused by imperfect screening in competitive credit markets. We find that imperfect screening may, depending on the parameters of the model, generate excessive screening, inefficient duplication of screening or screening cycles. Whenever screening cycles occur they are manifestations of either socially excessive or insufficient screening. We present a full equilibrium characterization and a welfare analysis. The implementation of socially optimal lending decisions requires communication across lenders (i.e. information sharing), which decentralized markets typically cannot achieve.
\end{abstract}

JEL Classification: G24, G21, G14, L10

Keywords: screening cycles, competitive credit markets, credit tests, information acquisition, informed funding

Thomas Gehrig

Institut zur Erforschung der Wirtschaftlichen Entwicklung

University of Freiburg

DE-79085 Freiburg

GERMANY

e-mail: thomas.gehrig@vwl.freiburg.de
Rune Stenbacka

Department of Economics

Swedish School of Economics

P.O. Box 479

FI-00101 Helsinki

FINLAND

e-mail: rune.stenbacka@hanken.fi

* We are grateful for the comments by seminar participants at the Swedish School of Economics, London School of Economics, ESSEC Paris, University of Frankfurt, Ente Luigi Einaudi, Fondation Banque de France, Deutsche Bundesbank, Mannheim University, Bank of Finland, University of Pennsylvania, the American University, the EEA meeting in Venice, the NORIO workshop in Copenhagen and the BIS-JFI conference in Basel. We are grateful for the comments of Elena Carletti, Hans Gersbach, Luigi Guiso, Robert Hauswald, Martin Hellwig, Heinz Herrman, Dirk Krüger, Joshua Lerner, Dima Leshchinski, Robert Marquez, Michel Robe, Andrei Sarychev, Frank Schorfheide, Per Strömberg, Anjan Thakor, Hannu Vartiainen and in particular our discussant Javier Suarez. Philip Jung, Almira Buzaushina and Carola Gross provided excellent research assistance. Financial support of the Academy of Finland, the DAAD, the Deutsche Forschungsgemeinschaft (DFG), the Hanken Foundation, the Yrjö Jahnsson Foundation, and the Volkswagenstiftung is gratefully acknowledged. 


\section{Introduction}

For many decades research in economics has explored how a decentralized economic system performs relative to a social optimum. By and large, there is consensus, that competitive markets perform well, when the commodities are given and when the price system can communicate and coordinate all relevant information. (e.g. Hildenbrand, 1982). The basic tenet of information economics posits that under informational asymmetries, non-market institutions typically tend to Pareto-dominate market mechanisms. So how do decentralized systems perform, when the commodity space itself is endogenous, or when some of the commodities need to be invented first, before they can be traded? In this case both of these two conditions stated for the beneficial working of a market system are violated: the product space is not fixed and the information about future innovations is highly asymmetric between inventors, possible financiers and potential ultimate users. Will decentralized systems still work satisfactorily under such conditions? How do decentralized, and hence competitive, markets perform as "discovery procedures" (v. Hayek (1969))?

The answer to this question might have far-reaching implications. If v. Hayek was right, why do we then, for example, observe such a strong political pressure for interventionist policies in Europe (Lisbon strategy) or Asia? ${ }^{1}$

In their studies of the architecture of economic systems Sah and Stiglitz (1986, 1988) argue that decentralized market-based systems tend to generate more innovations than bureaucratic and centralized economics systems. And, indeed, innovative activity thrives under conditions of decentralized financing as can be witnessed in countries with active venture capital markets. As Sah and Stiglitz have pointed out, when information is incomplete and individual assessments are imperfect, decentralized decision procedures will give greater chances for truly good projects to be eventually identified and therefore implemented. On the other hand, in decentralized markets truly bad projects also benefit from additional chances for financing. Hence, quite generally a decentralized market system tends to provide financing to more projects - both good and bad ones. However, in the models of Sah and Stiglitz information is exogenously fixed. To the extent that rejected applications return to the pool of unscreened entrepreneurs, the information

\footnotetext{
${ }^{1}$ For more detailed discussions of related issues we refer to, for example Bolton and Farrell (1990).
} 
about a previous negative screen is socially lost, and the pool of applicants becomes adversely selected. Obviously, this screening externality will affect the incentives of other financiers to produce information. This poses the following question: Can a market-based system induce socially optimal production and aggregation of information at all? $?^{2}$

While Broecker (1990) was the first to analyze the impact of the negative screening externality on competition, we analyze the impact of this screening externality on information production in a decentralized market. In particular we explore the dynamic properties of decentralized screening in competitive financial markets. How do markets perform from a societal perspective? Should the costs of acquiring information on projects seeking funding be subsidized, or should they be taxed? How can potential market failures in the market for project screening be recognized by outside observers? Answers to these questions figure high on the European policy agenda, since inefficiencies in venture financing are widely made responsible for the lackluster growth performance of the European Union in a global perspective.

We provide a simple dynamic model of competitive start-up financing. We assume that screening requires resources, as is typical in the venture capital industry. For our simple setting we can work out a complete characterization of the market equilibrium configurations and how their qualitative nature depends on crucial underlying parameters, in particular the screening costs, imperfections in the screening technology and the potential project returns.

Compared to the first-best screening regime we find that excessive screening may emerge as an equilibrium in a range of intermediate screening costs. Also, for sufficiently low screening costs we find that the screening activities are typically not socially optimal for a certain range of project returns. Interestingly, even when the pool of new projects is stationary, we find parameter constellations with screening cycles such that periods of screening are followed by periods of inactivity and vice versa. Screening cycles are always evidence of inefficient information acquisition, and imperfections in

\footnotetext{
${ }^{2}$ In the case of fixed information markets are superior to bureaucracies whenever the social cost of (erroneously) denying truly good projects exceed the social cost of (erroneously) adopting truly bad projects.
} 
the screening technology are necessary for their emergence. In our model cycles typically result from excessive screening whenever they occur.

Decentralized screening generates cycles even in a stationary environment because project-specific information produced in earlier rounds of screening is proprietary information so that no social memory is created. Unworthy projects, which are rejected by a given financier, may apply to some other financier in later rounds. By so doing they tend to worsen the quality of the overall project pool as long as the screening technology is informative. If in a given period the pool is sufficiently adversely selected, all financiers may prefer to halt their screening activities and wait until sufficiently many new projects have entered and improved the average pool quality to render screening profitable again. So the inactivity is caused by the pool-worsening effect of decentralized search by the project holders. From a social point of view this inactivity implies that the funding, and thereby implementation, of creditworthy projects is delayed. Moreover, screening cycles may interact with other sources of dynamic instability, as will be briefly discussed in the concluding section.

Our analysis proceeds as follows. Section II presents our basic model with costly screening. Section III characterizes market outcomes under competitive screening. In section IV we compare the market outcome with the first best solution and provide a short policy discussion. Section V summarizes and lays an agenda for future research.

\section{A Model with Costly Screening}

Consider the following simple dynamic setting with adverse selection with respect to risky projects of unobservable types. A proportion $\lambda$ of the projects is of creditworthy (good) type, whereas the remaining proportion $1-\lambda$ never generates any positive cashflow. ${ }^{3}$ Each project requires one unit of funding. A good project returns a cash flow of $R_{G}$ in case of success and nothing otherwise. The probability of success is $\pi \in[0,1]$.

While entrepreneurs develop project ideas they require outside funding. For reasons of tractability we assume they have no funds of their own. Potential financiers

\footnotetext{
${ }^{3}$ This is a convenient simplification. In fact we only need that expected returns do not cover the opportunity costs of funding.
} 
such as banks or venture capitalists can invest their funds either in the capital market at the risk free rate normalized to zero or in entrepreneurial projects with the return profile characterized above. Financiers are risk neutral. Thus the ventures are potentially attractive only when their expected return exceeds the opportunity cost of funding, i.e. $\pi R_{G}>1$, since entrepreneurs are assumed to be protected by limited liability.

The innovation activities are particularly risky for outside financiers because of their very nature. Investors typically do not have the particular project- and industryspecific knowledge, which is necessary to make informed funding decisions. This is why extensive, and hence costly, screening of innovative projects by experts and why proper contractual design are crucial features for successful outside funding of such ventures. We here, for simplicity, capture these aspects by assuming that the financiers have access to a screening or testing technology that generates information about the underlying project type. The test costs $c>0 .{ }^{4}$ Moreover and importantly, we assume that this test is imperfect. While the test identifies good projects with certainty, it may misclassify truly bad projects with a positive probability $\beta>0 .^{5}$

The market operates dynamically over time without discounting. We consider a stationary framework in discrete time where in each period a unit mass of new ventures enters the pool of potential projects in need of funding. Those projects live for two periods. Hence they can apply for funding in the first period immediately after entering the pool, and, if rejected, again in the second period. Thereafter they are worthless and decay.

It is worth emphasizing that at any point in time the pool of potential projects in need of funding consists of new projects, a portion $\lambda$ of which are of good quality, plus a mass of projects rejected by other financiers in the previous period. Given that screening is informative, this pool tends to be more adversely selected than the pool of new projects entering the market in each period. This negative screening externality has been

\footnotetext{
${ }^{4}$ These costs are typically substantial. For example, Bengtsson et al. (2002) demonstrate that successful applications in the venture capital industry typically require a screening period ranging from a couple of weeks up to a few months. This is expert management time.

5 Again we could also allow misclassifications of good projects, and thus generalize our argument (e.g. Gehrig and Stenbacka (2004)).
} 
identified first by Broecker (1990) in a static framework. In this paper we analyze the dynamic implications of this screening externality in competitive markets.

Strategic decisions are as follows. In each period $t$, financiers announce lending rates at which they are committed to fund a project if this has been classified as a good project. In doing so, financiers need to take into account their screening activities in that period. Alternatively, the financiers can also choose to grant funds without screening in order to economize on screening costs. And finally the financiers can decide to remain inactive altogether.

This completes the description of the basic model. We proceed to characterize screening and financing decisions in a decentralized market in section III. In section IV we subsequently extend our analysis to the case of a coordinated allocation. This will allow us to compare market outcomes with first best allocations.

\section{Funding Equilibrium in Decentralized Markets}

In this section we present a complete characterization of the market equilibrium with an emphasis of showing how its qualitative nature depends on crucial underlying parameters, in particular the screening costs, imperfections in the screening technology and the potential project returns. Our main interest is the analysis of the implications of the screening externality in large decentralized markets. In such markets a previously rejected entrepreneur has a second chance to apply for funding. We will assume that the pool of financiers is of unit mass, which is equivalent to assuming no recall for the financiers, since a given entrepreneur will almost surely never be re-matched with a financier who previously rejected his project. Given that screening is imperfect and that occasionally truly bad projects will receive funding, there is always a positive incentive on behalf of the project holders to apply for funding, even when the underlying ventures are truly bad. ${ }^{6}$

Given the overlapping generations structure of the projects, in each period there are at most two vintages of projects bidding for funding, new and seasoned projects.

\footnotetext{
${ }^{6}$ In our setup the benefits of a further application always exceeds the cost of such an application, which we fix at zero. So each applicant - good or bad - will apply again. (Of course, good types will not have to submit a second bid, since, by assumption, they are classified correctly.)
} 
Since the pool of seasoned projects has already been previously tested it is more adversely selected than the pool of new incoming projects. Hence the screening activity across periods may be state dependent, where the state consists of the screening activity in the previous period.

We here consider only the discrete states of unscreened funding (A), of screened funding $(\mathrm{S})$ and of inactivity $(\mathrm{N})$. The case of mixed strategies is briefly discussed later in section $\mathrm{V}$.

After a period of unscreened funding, the project pool consists only of new projects, since all seasoned projects have received financing and, consequently, have left the pool of project applicants. Unscreened funding will occur as a stationary competitive equilibrium, when two conditions are met: i) the repayment rate $R_{t}^{*}$ of unscreened lending recovers the ex-ante insolvency risk, $R_{t}^{*} \geq \frac{1}{\lambda \pi}, t=1,2, \ldots$, and ii) the cost of screening is sufficiently high so that it exceeds the associated reduction in the risk premium of the competitive lending rate. In general, screening is valuable because it reduces funding costs by eliminating bad projects. The proportion of unworthy projects is $1-\lambda$, and, since the test is imperfect, only a portion of $1-\beta$ of those can be eliminated by screening. Accordingly, screening is economically viable as long as screening costs are sufficiently low, i.e. $c<(1-\lambda)(1-\beta)$.

\section{Proposition 3.1 (high cost of screening):}

When $c \geq(1-\lambda)(1-\beta)$ there are dynamic competitive equilibria that either consist of

i) unscreened financing in each period, when $R_{G} \geq \frac{1}{\lambda \pi}$, or

ii) inactivity in each period, when $R_{G}<\frac{1}{\lambda \pi}$.

Proof: See Appendix.

At a lower cost of screening, however, a dynamic equilibrium with unscreened funding in each period is no longer viable. In this case, screening has the potential to 
generate information, which is sufficiently valuable to cover the screening costs. Competition ensures that those potential efficiency gains are exploited. But at the same time uncoordinated screening generates a negative pool externality, because the rejected projects get another chance to submit a bid. This interplay between the informational value of screening and the pool externality generates three different dynamic patterns. When the informational value is sufficiently large relative to the costs of screening, a dynamic equilibrium consists of screening in each period. With a moderate informational value, periods of screening are followed by a period of inactivity. Screening is not profitable until the pool is sufficiently improved by the entry of new projects into the pool of applicants. Under precisely this configuration screening cycles will occur. In our simple framework these cycles turn into 2-cycles, i.e. cycles where screening and inactivity alternate so as to generate cycles with a length of two periods. When the screening costs are sufficiently large relative to project repayments, lending will break down in each period. These results are rigorously formulated in the next proposition.

\section{Proposition 3.2 (moderate and low cost of screening):}

When $\quad c \leq(1-\lambda)(1-\beta) \frac{2-\beta}{1+(1-\lambda)(1-\beta)}$ there are dynamic competitive equilibria that either consists of

i) screening in each period with a lending rate

$$
\begin{aligned}
& R_{S S}=\frac{\lambda+(1-\lambda) \beta(2-\beta)}{\lambda \pi}+\frac{(1+(1-\lambda)(1-\beta)) c}{\lambda \pi}, \text { when } \\
& R_{G} \geq \frac{1}{\lambda \pi}((\lambda+(1-\lambda) \beta(2-\beta))+(1+(1-\lambda)(1-\beta)) c) \text { or }
\end{aligned}
$$

ii) regular 2-cycles with screening and lending at rate $R_{N S}=\frac{\lambda+(1-\lambda) \beta}{\lambda \pi}+\frac{c}{\lambda \pi}$ following each period of inactivity, when

$$
\frac{1}{\lambda \pi}((\lambda+(1-\lambda) \beta)+c) \leq R_{G} \leq \frac{1}{\lambda \pi}((\lambda+(1-\lambda) \beta(2-\beta))+(1+(1-\lambda)(1-\beta)) c)
$$

and additionally $c \leq(1-\lambda)(1-\beta)$ 
or

iii) inactivity in each period, when

$$
R_{G}<\min \left\{\frac{1}{\lambda \pi} \quad, \quad \frac{1}{\lambda \pi}((\lambda+(1-\lambda) \beta)+c)\right\}
$$

Proof: See Appendix.

Propositions 3.1. and 3.2 provide a full characterization of the competitive market equilibria in our lending market. Figure 1 provides an illustration in a $\left(c, R_{G}\right)$-diagram for given parameter combinations of $\lambda, \pi$ and $\beta$. Screening cycles occur in region A.

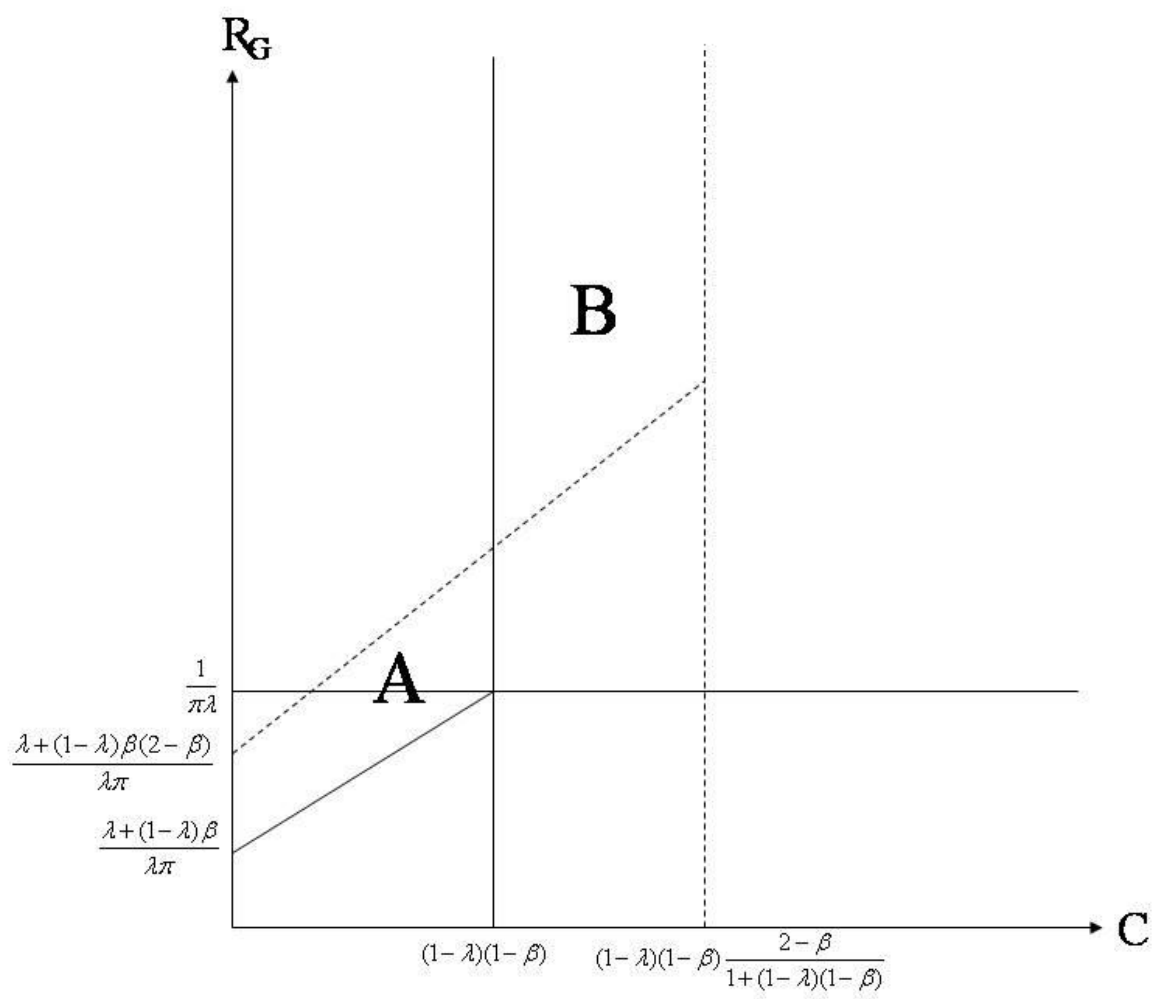

Figure 1: Characterization of market equilibrium: screening cycles occur in region A, multiple equilibria in region $B$. 
Observe that the conditions on screening costs in Propositions 3.1 and 3.2 define overlapping regions for c. Moreover, it holds true that $(1-\lambda)(1-\beta)<(1-\lambda)(1-\beta) \frac{2-\beta}{1+(1-\lambda)(1-\beta)}$. Accordingly, in this parameter range, denoted B in Figure 1, there are multiple equilibria for sufficiently high project returns. We highlight this feature in the next corollary.

\section{Corollary 3.3 (multiplicity of market equilibria)}

In the range $(1-\lambda)(1-\beta) \leq c \leq(1-\lambda)(1-\beta) \frac{2-\beta}{1+(1-\lambda)(1-\beta)}$ (region $B$ in Figure 1$)$ there are market equilibria both with stationary screening in each period and with stationary unconditional financing in each period, if project characteristics satisfy $R_{G} \geq \frac{1}{\lambda \pi}((\lambda+(1-\lambda) \beta(2-\beta))+(1+(1-\lambda)(1-\beta)) c)$.

Proof: Immediate from Propositions 3.1 and 3.2.

Multiplicity of equilibria is a first manifestation of the pool worsening effect in a dynamic context. Because of the pool worsening effect the returns of screening are higher, if there has already been screening in the previous period. This is why the critical screening cost threshold is higher if there has been screening in the previous period. In this case screening will cut costs more efficiently than if there had been inactivity or acceptance of all project applications in the earlier period. Hence screening is more valuable subsequent to a period of screening, but, on the other hand, it then focuses on an adversely affected pool.

It should also be emphasized that our model predicts screening cycles as an equilibrium phenomenon, under the circumstances characterized in Proposition 3.2 (ii), in an otherwise completely stationary environment. These cycles constitute another manifestation of the pool worsening effect of uncoordinated screening. The pool worsening externality induced by screening in a given period can deteriorate pool quality in the subsequent period to such an extent that screened lending does not become profitable again until the quality of the pool of applications has recovered sufficiently through the entry of the new generation of projects in the next period. Screening-induced 
lending cycles of this type will occur for the combination of sufficiently small screening costs and moderate project returns. It should be emphasized that the presence of classification errors is a necessary element behind the emergence of these screening cycles. Namely, in a formal sense the region with parameter combinations leading to screening cycles shrinks and disappears in the limit as the probability for a classification error approaches zero.

Screening cycles occur under conditions where the pool of applicants is adversely selected to a sufficient degree. These conditions are most likely met in the venture capital industry. Bengtsson et al. (2002) provide evidence about substantial costs of screening for a particular venture capital fund. They report that the acceptance rate in their sample ranges from 2 to 5 percent, and that the screening process typically involves several rounds of increasing screening intensity by highly qualified experts. Thus screening typically involves significant delay in the order of several weeks and even months until approval of a single successful project. It also comprises significant opportunity costs in terms of expert salaries.

The emergence of screening cycles is very interesting in relationship to the important literature on financial accelerator effects. Existing theories of financial accelerator effects (summarized by, for example, Bernanke, Gertler and Gilchrist (2000)) emphasize mechanisms whereby adverse shocks to the economy are endogenously amplified and propagated by credit market imperfections. In contrast to these theories focusing on how asset price fluctuations are amplified and propagated by credit market imperfections our theory does not require the existence of exogenous stochastic shocks. Instead the cycles are generated based on a mechanism emphasizing the pool-worsening effects associated with decentralized screening within the framework of a stationary environment. Our model shares the ability to generate cycles in an otherwise stationary environment with Suarez and Sussman (1997). However, the mechanism is completely different because in Suarez and Sussman the credit cycles are essentially generated by state contingent incentives for risk taking on behalf of project holders, whereas the screening activities on behalf of financirs are the source of cycles in our model.

When the screening costs are sufficiently low relative to the potential cashflows, screened finance prevails. Under such circumstances the screening externality manifests itself as a higher risk premium incorporated in the lending rate. 
Does the competitive credit market grant funding under those circumstances when it is efficient and are the terms of lending efficient? What can be said about the socially optimal amount of screening? Since Propositions 3.1 and 3.2. provide a full characterization of the competitive equilibrium, we can conduct a complete welfare analysis. This is the topic of the next section.

\section{Welfare Analysis}

The welfare analysis is particularly simple in our framework. Due to the inelastic demand of funding, the monopoly allocation is an allocation, which actually maximizes total surplus. Hence, we can compare the equilibrium allocations with the monopoly allocations.

In contrast to the decentralized market allocation, the monopolist does not suffer from the screening externality. We assume that a monopoly financier has full recall of earlier project applications. Hence formerly rejected applicants do not enjoy a second chance. How will this implicit inter-temporal coordination affect screening and lending?

Clearly, with the market structure of a monopoly the financier can collect all surplus based on the unchallenged market power. Hence pricing is straightforward. The interesting issue, however, is to analyze the funding, and more precisely the screening, decision of the financier in a monopoly position. As before, the monopolist may select among three lending strategies: (i) inactivity (no lending and no screening), (ii) screening and lending to projects classified as creditworthy and (iii) universal lending without screening. The optimal behavior of the monopoly financier is characterized in Proposition 4.1.

\section{Proposition 4.1: (monopoly financier)}

The monopoly financier chooses

i) unscreened finance (A) if $c \geq(1-\lambda)(1-\beta)$ and $R_{G} \geq \frac{1}{\lambda \pi}$

ii) $\quad$ screened finance (S) if $c<(1-\lambda)(1-\beta)$ and $R_{G} \geq \frac{\lambda+(1-\lambda) \beta+c}{\lambda \pi}$

iii) inactivity $(N)$ otherwise.

Whenever lending occurs the monopoly financier claims the full surplus, i.e. $R^{*}=R_{G}$. 
Proof: See Appendix.

The results are straightforward. The monopoly grants unscreened finance, when screening costs are sufficiently severe so as to outweigh the informational value of screening. Of course, unscreened funding takes place only insofar as project quality is sufficiently high so as to cover the ex-ante risk premium associated with the unscreened project pool. For sufficiently low screening costs, it is optimal for the monopoly financier to grant screened funding as long as the projects identified through screening are creditworthy in the sense that they are associated with sufficiently high expected returns. Only when screening plus lending costs cannot be covered, inactivity will result. This happens for the combination with sufficiently high screening costs and sufficiently low returns for a successful project.

When the characteristics of the entering pool of new project applications is invariant over time, the monopoly financier's behavior is, unsurprisingly, always stationary. Hence, in an otherwise stationary environment cycles must necessarily be interpreted as manifestations of inefficiencies. But which way does the inefficiency go? Is there excessive screening or is there insufficient information production?

Figure 2 compares the regimes of Propositions 3.1, 3.2. and 4.1. From this we can see that the social optimum differs from potential market outcomes in regions A and B. Decentralized competition generates cycles for sufficiently low screening costs (area A) for a certain range of project returns. As we can infer from Proposition 4.1 (ii) it would be socially efficient to screen unconditionally in this case. In this parameter range, when evaluated over the whole 2-period screening cycle the market produces the same amount of information about creditworthy projects as a monopolist would do. ${ }^{7}$ However, the decentralized market allocation generates delay in order to prevent the duplication of information production about bad projects. Hence creditworthy projects will receive

\footnotetext{
7 It is straightforward to modify the basic model such that in this range the market provides strictly less information about good projects relative to the first best. For example, if a sufficiently small portion $\varepsilon$ of new projects already dies after the first period, by continuity the qualitative properties remain valid. However, in this case some good projects will definitely not be financed in states of inactivity associated with a cyclical market equilibrium.
} 
funding every second period only. In this respect, the competitive market outcome induces a social cost associated with delayed information production even though all projects are ultimately screened.

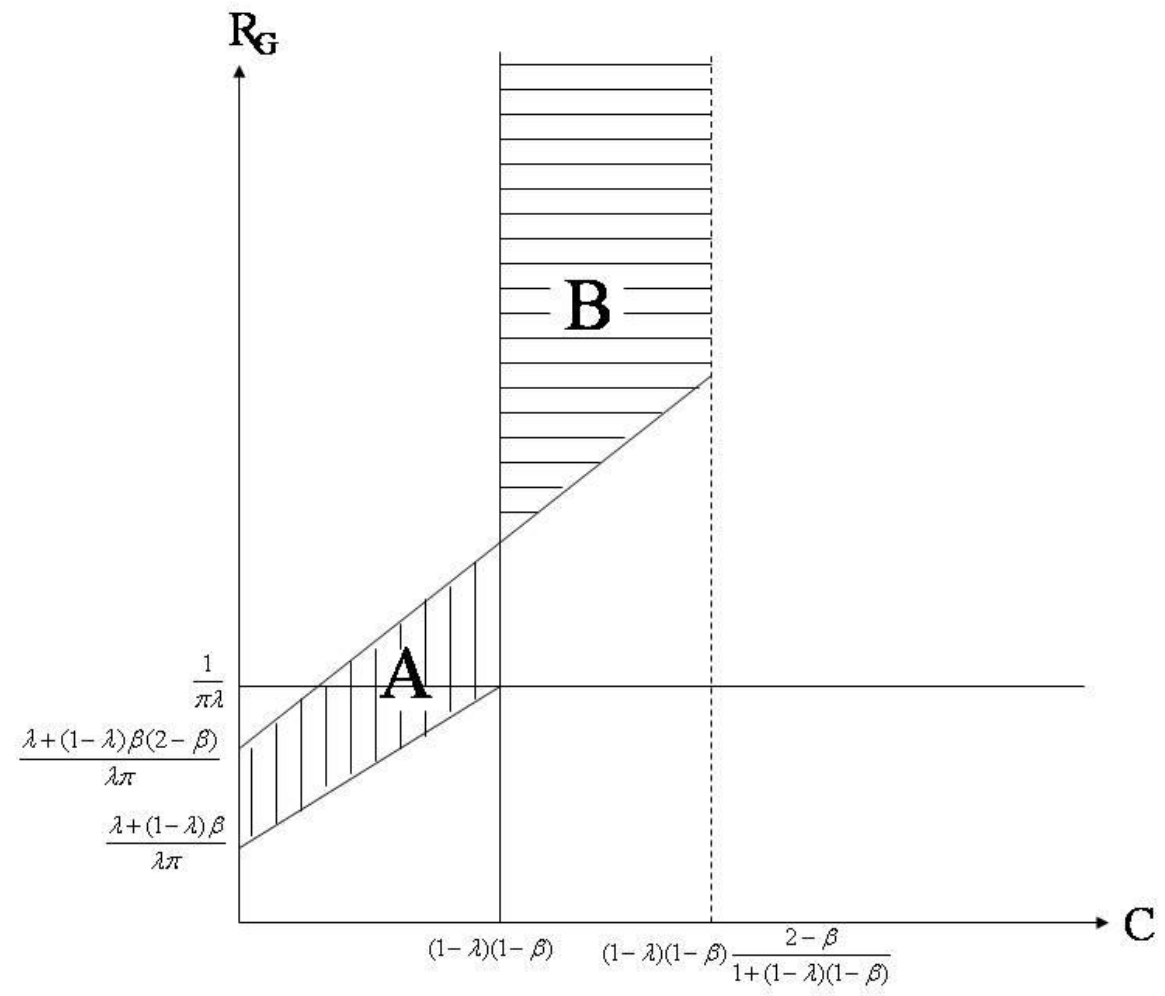

Figure 2: Welfare consequences: cycles in region A, exzessive screening in region $B$.

For sufficiently high screening costs we know from Corollary 3.3 that there are multiple equilibria with some involving screening (region B). In light of Proposition 4.1 (i) the equilibrium with unconditional financing as described in Proposition 3.1 is efficient under those circumstances, whereas the equilibrium with constant screening (Proposition 3.2) is inefficient in this range. Here screening results from rent seeking in decentralized markets. Since competitors screen each financier faces a pool of applicants which is adversely selected to such an extent that unscreened financing is not viable in equilibrium. In this respect the pool-worsening effect induced by competition is also in this range the mechanism behind the inefficiency associated with the equilibrium with constant screening. On the other hand, in a no-screening equilibrium the cost of screening is not warranted by the pool characteristics as long as all competing financiers (rationally) abstain from screening. Clearly, for this parameter configuration the 
screening equilibrium is associated with too much information production compared with the social optimum. In this range a ban on screening would achieve a Paretosuperior outcome.

Only when screening costs are high enough such that screening is not viable as a market outcome the market equilibrium is again efficient.

In summary, we have found that in our framework the market equilibrium never induces insufficient information production. Nevertheless under many circumstances (parameter configurations captured by regions $\mathrm{A}$ and $\mathrm{B}$ in Figure 2) the market equilibrium is socially inefficient, and the nature of this inefficiency is highly contingent on the magnitude of the screening costs. With sufficiently low screening costs the market equilibrium is characterized by screening cycles. Under these circumstances the competitive market outcome induces a social inefficiency associated with delayed information production even though all projects are ultimately screened. For sufficiently high screening costs there are multiple equilibria. Under such circumstances the equilibrium characterized by repeated screening induces excess information production compared with the social optimum. The pool-worsening effect of screening is essentially the source of the market failure whenever the decentralized project evaluation induces inefficiencies, no matter whether these take the form of delayed information production as in the configuration with screening cycles or simply excess screening as in the case with equilibrium with repeated screening for the range of intermediate screening costs.

\section{Discussion}

In this section we discuss the robustness of our analysis. In section i) we explore to what extent the result about excessive information production is robust. Could it be possible that markets provide too little information? In section ii) we analyze the implications of allowing randomized screening and lending strategies.

\section{i) Excessive Information Production}

Our analysis of the cycling region in section IV reveals that good projects are always screened, as long as screening takes place. However, there tends to be excessive screening of bad projects relative to coordinated funding. Moreover, there is a parameter 
region with multiple equilibria where in one of these equilibria screening does occur even even though a monopolist financier would lend on good faith without screening. So information production can be excessive in decentralized markets. Is this a general feature of decentralized markets?

The answer is no. A slight modification of our model demonstrates that markets may generate too little valuable information. For example, let us modify our model so that a small portion $0<\varepsilon<1$ of each project cohort is viable for only one period. Assume that this holds for good and bad projects alike.

This modification does not change the monopolist's decision problem. The optimal behavior of the monopoly financier is stationary anyway, so all good projects will be funded, whenever it is socially efficient to do so.

But also the decision problems of competitive financiers remain unchanged as long as the proportions of good and bad projects remain constant, which we assume. Hence cycling will still occur in decentralized markets for the same parameter values as established in the base model. However, in contrast to the base model, creditworthy projects are now not only delayed, but they are denied altogether generating increased welfare costs. A coordinated lending industry would provide funding even to those projects.

\section{Proposition 5.1 (inefficient cycles)}

Screening cycles occur in competitive markets under the conditions of Proposition 3.2 (ii). In addition, when $R_{G}>\frac{\lambda+(1-\lambda) \beta+c}{\lambda \pi}$ the coordinated stationary screening outcome strictly Pareto-dominates the uncoordinated outcome with screening cycles.

Consequently, whenever cycles occur, a small portion $\varepsilon$ of projects entering in periods of inactivity will leave the market unscreened. From a social point of view this is good if bad projects are eliminated that way. But on the other hand also the potential surplus of the good projects is lost for society. Under the conditions of Proposition 5.1 this loss strictly dominates the gain from avoiding lending to bad borrowers. So the net effect is socially harmful. Screening cycles are strictly dominated by stationary coordinated screening. 
By way of summarizing, in decentralized markets two sources of inefficiency may occur. Insufficient information production on worthwhile projects can occur under decentralized information production under conditions that generate cycles, while quite generally there is inefficient duplication of information production on unworthy projects.

\section{ii) randomized lending}

One might argue that screening cycles may emerge as a consequence of time clustering and the artificial restriction to exclude randomization strategies. While there may be good reasons to argue that randomization in lending decisions is unlikely to be empirically relevant to a large degree, of course, it would be difficult to empirically prove such a conjecture. Therefore, we explore directly how randomization would affect our results.

First, of course, as before the monopolist financier would not randomize at all. The monopolist has incentives to adopt a pure strategy. The market outcome, however, would change in character. In particular, the screening cycles would disappear with randomization. Nevertheless, the pool worsening externality will still arise, whenever competitive screening takes places with positive probability.

\section{Proposition 5.2. (randomization)}

When financiers are allowed to randomize with respect to their screening decision, the region of screening cycles is replaced by completely mixed screening strategies.

Proof: See Appendix.

Randomization only affects the regions with non-stationary strategies of Proposition 3.2. All other regions remain unmodified. In particular, the pool worsening externality applies to the randomized equilibrium strategies as well. Accordingly, the welfare result about excessive screening remains robust with respect to this generalization. 


\section{Policy Implications}

As our welfare analysis has made clear, the nature of the potential market failure associated with competitive screening decisions is contingent on the combination of screening costs, classification imperfections and project returns in case of success. Furthermore, it is not advisable to design policy recommendations, for example tax/subsidy policies, which are highly sensitive to project-specific information, which the policy maker is unlikely to observe. Under all circumstances subsidies to improve financing conditions for innovative firms tend to be contra-productive in our framework. Essentially, the screening activities per se should not be subsidized, since generally screening attracts too extensive resources in competitive markets anyway. Furthermore, project subsidies will act like an improvement in cash flows, and thus increase the likelihood of screened finance, without altering the fundamental values to society. This warning is in stark contrast to some recent papers that tend to emphasize positive externalities in the financing of innovative ventures (e.g. Keuschnigg and Nielsen (2003)).

The pool-worsening effect of screening is essentially the source of the market failure whenever the decentralized project evaluation induces inefficiencies, no matter whether these take the form of delayed information production as in the configuration with screening cycles or simply excess screening as in the case with the equilibrium associated with repeated screening for sufficiently high screening costs. With this poolworsening effect of uncoordinated screening as the crucial source of the market failure, the question arises of whether and, in that case, how the required coordination in screening can be achieved as part of a decentralized mechanism.

On the basis of our analysis information sharing seems an obvious candidate. In fact, information sharing is a wide-spread institution for consumer credit and commercial lending. In some countries information sharing is based on private initiative, whereas in other countries it is delegated to public institutions (see, Japelli and Pagano (2002)). Interestingly, contrary to the traditional banking industry there is no public information sharing mechanism in the venture capital industry.

Indeed there may be many reasons why one would not expect that information sharing will work under all circumstances, and for funding innovative projects in 
particular. Gehrig (2004) has shown how information sharing may adversely affect incentives to collect high quality information, when the quality of information is a strategic choice variable. Gehrig and Stenbacka (2007) have theoretically established that information sharing may in fact magnify oligopoly rents in imperfectly competitive markets largely at the expense of good (innovative), but financially constrained projects without an established credit record. In addition, information sharing is a well-known mechanism to facilitate tacit collusion. ${ }^{8}$ Consequently, information sharing requires strict enforcement of competition policy. Otherwise information sharing may imply that truly good innovative entrepreneurs face higher funding costs. This requirement contrasts with the view that banking supervisors often implicitly tolerate a certain degree of market power in order to increase the safety and soundness of the financial industry. We do not necessarily negate the potential need of such prudential supervisory policies. However, whenever such prudential policies are applied, the potential total benefits of information sharing may be offset by associated harmful effects on competition. This holds true because the potential of information sharing to reduce the pool worsening externality is then offset by the tendency of information sharing to soften competition among financiers.

\section{Concluding Comments}

Our analysis has highlighted the role of the inter-temporal screening externality induced by competition as a structural source of instability in financial markets granting unsecured project funding. While earlier work focusing on banking markets has already emphasized the potentially harmful consequences of competition with respect to screening in banking (Broecker (1990)), our article is the first analysis drawing out the dynamic implications of the screening externality with perfect competition. We demonstrated how endogenous information acquisition in markets with unsecured funding and characterized by asymmetric information can create lending cycles as long as competing financiers undertake their screening decisions in an uncoordinated way. In the environment of our model such screening cycles emerge in response to competition

\footnotetext{
${ }^{8}$ For an insightful discussion of the antitrust implications of this mechanism we refer to Kühn (2001).
} 
between financiers, whereas project-specific information exchange between financiers or cartelization of the funding industry would eliminate such fluctuations.

We explored the welfare implications of decentralized screening competition for different parameter configurations with respect to the screening costs, screening imperfections and project returns and we also emphasized the role of imperfections in the screening technology. We found that excessive screening may emerge as an equilibrium for a range of intermediate screening costs. Furthermore, for sufficiently low screening costs we found that the screening activities are typically not socially optimal for a certain range of project returns. Even with a stationary pool of new projects we characterized parameter constellations with screening cycles, i.e. periods of screening are followed by periods of inactivity and vice versa. Screening cycles are always evidence for screening inefficiencies.

Screening cycles may also interact with other sources generating industry and business cycle dynamics. For example, some significant recent studies have developed models of financial accelerator effects, which emphasize mechanisms whereby adverse shocks to the economy are endogenously amplified and propagated by credit market imperfections. These models were surveyed within a dynamic general equilibrium framework by, for example, Bernanke, Gertler and Gilchrist (2000). On an intuitive level already Fisher (1933) discussed how credit constraints propagate the effects of shocks on aggregate output and asset prices. According to Fisher, the more the private sector places emphasis on solving its debt problem the deeper the economy will be caught in a debt trap. Kiyotaki and Moore (1997) provided an influential model of a dynamic economy where borrowers' credit limits are affected by the prices of the collateralized assets. Their analysis showed how the dynamic interaction between credit limits and asset prices will constitute an important transmission mechanism whereby shocks to the economy persist, amplify and spill over across different sectors. In contrast to these theories focusing on how asset price fluctuations are amplified and propagated by credit market imperfections our theory does not require the existence of exogenous stochastic shocks.

In line with our model, Suarez and Sussman (1997) have developed a theory for how credit cycles may emerge as an equilibrium phenomenon in an otherwise stationary equilibrium. However, Suarez and Sussman presented a mechanism centered around moral hazard, not adverse selection. More precisely, during booms expanded production leads to lower prices, which increase the need for external finance. But, a higher debt 
burden leads to excessive risk taking and an associated high rate of business failures, i.e. a bust. During a bust, production is contracted and prices increase, which improves the liquidity reserves of firms. This in turn mitigates the moral hazard problems, leading to lower risk taking and the economy heads towards a boom again.

Whenever they occur, screening cycles are manifestations of a market failure. This type of market failure derives from limitations of communication in decentralized markets. Hence, in our theory it seems that information exchange could prevent cycles. On the other hand, information exchange may also soften competition and facilitate collusion. Likewise, cycles will not emerge in cartelised or even monopolistic financial markets. This leaves an interesting design problem for future research of how to stabilize the screening activities without sacrificing other benefits of decentralized competition. 


\section{References}

Bernanke, B., Gertler, M. and S. Gilchrist, 2000, The Financial Accelerator in a Quantitative Business Cycle Framework. In J. Taylor and M. Woodford, eds., Handbook of Macroeconomics, Amsterdam, North-Holland, chapter 21.

Bengtsson, O., S. Kaplan, F. Martel, P. Strömberg (2002): Investments Screening and Market Conditions: Evidence from Venture Capital, mimeo.

Bolton, P. and J. Farrell, 1990: Decentralization, Duplication, and Delay, Journal of Political Economy 98, 803-826.

Broecker, T. , 1990: Credit-Worthiness Tests and Interbank Competition, Econometrica $58,429-452$.

Fisher, I., 1933: The Debt-Deflation Theory of Great Depressions, Econometrica 1, 337357.

Friedman, B. and K. Kuttler, 1993: Economic Activity and the Short-Term Credit Markets: An Analysis of Prices and Quantities, Brookings Papers of Economic Activity, 193-266.

Gehrig, T., 1998: Screening, Cross-Border Banking, and the Allocation of Credit, Research in Economics 52, 387-407.

Gehrig, T. and R. Stenbacka, 2001: "Screening Cycles", CEPR-Discussion Paper 2915.

Gehrig, T. and R. Stenbacka, 2005: "Venture Cycles: Theory and Evidence", in V. Kanniainen, C. Keuschnigg (eds.): Venture Capital, Entrepreneurship, and Public Policy, MIT-Press, 151-177.

Gehrig, T. and R. Stenbacka, 2007: "Information Sharing and Lending Market Competition with Switching Costs and Poaching", European Economic Review 51, 7799.

Gersbach, H., 2001: Financial Intermediation, Capital Spillovers and Business Fluctuations, mimeo, University of Heidelberg.

Gertler, M. and S. Gilchrist, 1994: Monetary Policy, Business Cycles, and the Behavior of Small Manufacturing Firms, Quarterly Journal of Economics 109, 309-340.

Gorton, G. and P. He, 2005: Bank Credit Cycles, NBER working paper, 11363.

v. Hayek, F.A., (1968): Wettbewerb als Entdeckungsverfahren, Kieler Vorträge, N.F. 56, Kiel.

Hildenbrand, W. (1982): Information und Ressourcenallokation, Schriften des Vereins für Socialpolitik, N.F. 126, Information in der Wirtschaft, 9-31. 
Holmström, B. and J. Tirole, 1997: Financial Intermediation, Loanable Funds, and the Real Sector, The Quarterly Journal of Economics 112, 663-691.

Japelli, T. and M. Pagano, 2002: Information Sharing, Lending and Defaults: CrossCountry Evidence, Journal of Banking \& Finance 26, 2017-2045.

Kanniainen, V. and R. Stenbacka, 2000: Lending Market Structure and Monitoring Incentives, working paper, Swedish School of Economics.

Keuschnigg, C. and S.B. Nielsen (2003): Tax Policy, Venture Capital, and Entrepreneurship, Journal of Public Economics 87, 175-203.

Kiyotaki, N. and J. Moore, 1997: Credit Cycles, Journal of Political Economy 105, 211 248.

Kühn, K.-U., 2001: Fighting Collusion by Regulating Communication between Firms, Economic Policy 32, 169-204.

Rajan, R., 1994: Why Bank Credit Policies Fluctuate: A Theory and some Evidence, Quarterly Journal of Economics 109, 399-441.

Sah, R.K. and J. Stiglitz, 1986: The Architecture of Economic Systems: Hierarchies and Polyarchies, American Economic Review 76, 716-727.

Sah, R.K. and J. Stiglitz, 1988: Committees, Hierarchies and Polyarchies, The Economic Journal 98, 451-470.

Shaffer, S., 1998: The winner's curse in banking, Journal of Financial Intermediation 7, 359-352.

Suarez, J. and O. Sussman, 1997: Endogenous Cycles in a Stiglitz-Weiss Economy, Journal of Economic Theory 76, 47-71.

Sorenson, M. (2003): How Smart is Smart Money? An Empirical Two-Sided Matching Model of Venture Capital, mimeo, Stanford University. 


\section{Appendix:}

\section{Proof of Propositions 3.1 and 3.2:}

We find it convenient to prove the two propositions together. The split into two separate statements in the main text has been chosen for presentation purposes only.

Given the nature of projects financiers are confronted with a pool of projects that consist of two vintages at most.

Moreover there are three states in each period. The market can rest in inactivity $(\mathrm{N})$, it can be in screening regime $(\mathrm{S})$, and it can finance without screening $(\mathrm{A})$. The state in period $t$ - 1 determines the pool size and composition in period $t$. So after a period of inactivity, the project pool has size 2 and a quality $\gamma_{N}=\lambda$. After a period of screening in $t-1$, the pool consists of the new projects and bad projects that we denied finance previously, and hence bid for a second chance (by assumption good projects are always correctly classified and therefore leave the pool in a screening regime). In this case the

pool quality is $\gamma_{S}=\frac{\lambda}{1+(1-\lambda)(1-\beta)}$. After a period of unconditional financing (A), the pool of applicants only consists of new projects with quality $\gamma_{A}=\lambda$.

Depending on the state of the market in period $t$ competitive prices can be determined by a zero profit condition. So after a period of inactivity $(\mathrm{N})$ the market will rest in $(\mathrm{N})$. This will occur, whenever neither screened financing nor unconditional financing in $t$ can break even. Screening in $t$ is feasible if the competitive rate $R_{N S}$ does not exceed $R_{G}$. The competitive rate is determined by the zero-profit condition

$$
\lambda \pi R_{N S}-(\lambda+(1-\lambda) \beta)-c=0
$$

Likewise unscreened finance requires that the competitive lending rate after this history satisfies $R_{N A} \leq R_{G}$, where

$$
\lambda \pi R_{N A}-1=0
$$

After a state of screening the pool is adversely affected. Hence the zero profit condition for competitive screening is 


$$
\begin{gathered}
\lambda \pi R_{S S}-(\lambda+(1-\lambda) \beta+(1-\lambda)(1-\beta) \beta)-(1+(1-\lambda)(1-\beta)) c=0, \text { or equivalently: } \\
R_{S S}=\frac{\lambda+(1-\lambda) \beta(2-\beta)}{\lambda \pi}+\frac{(1+(1-\lambda)(1-\beta)) c}{\lambda \pi}
\end{gathered}
$$

and for unconditional finance $\lambda \pi R_{S A}-(1+(1-\lambda)(1-\beta))=0$, or equivalently

$$
R_{S A}=\frac{1+(1-\lambda)(1-\beta)}{\lambda \pi}
$$

Viability of screening or unconditional financing implies that $R_{S S} \leq R_{G}$ and $R_{S A} \leq R_{G}$, respectively.

Finally, after a state of unscreened finance (A) screening in period $t$ is viable if

$$
R_{A S}=R_{N S}=\frac{\lambda+(1-\lambda) \beta}{\lambda \pi}+\frac{c}{\lambda \pi} \leq R_{G}
$$

and unscreened finance is viable if

$$
R_{A A}=R_{N A}=\frac{1}{\lambda \pi} \leq R_{G}
$$

We can now offer a complete characterization of competitive equilibrium by analyzing the 9 potential two-period combinations of the three states.

First we note that screening dominates unconditional finance when screening costs are sufficiently low. (A.5) and (A.6) imply that after the states (A) or (N) screening dominates unconditional finance if

$$
c<(1-\lambda)(1-\beta)
$$

and (A.3) and (A.4) imply that after state (S) screening dominates if

$$
c<(1-\lambda)(1-\beta) \frac{2-\beta}{1+(1-\lambda)(1-\beta)} .
$$

Second we note that screening $(\mathrm{S})$ dominates inactivity $(\mathrm{N})$ after a period of screening, when $R_{S S} \leq R_{G}$, which according to (A.3) implies

$$
R_{G} \geq \frac{1}{\lambda \pi}((\lambda+(1-\lambda) \beta(2-\beta))+(1+(1-\lambda)(1-\beta)) c)
$$

Otherwise inactivity obtains after a period of screening. 
Screening dominates inactivity after a period of inactivity $(\mathrm{N})$ or unconditional finance (A) if $R_{N S}=R_{A S} \leq R_{G}$, which implies

$$
R_{G} \geq \frac{1}{\lambda \pi}((\lambda+(1-\lambda) \beta)+c) .
$$

Otherwise inactivity results.

Finally unconditional finance obtains after a period of unconditional finance (A) or inactivity $(\mathrm{N})$, whenever the unscreened pool is profitable, i.e.

$$
R_{G} \geq \frac{1}{\lambda \pi} \quad:
$$

With these observations we can characterize directly the stationary equilibria.

i) Unconditional financing (AA) will occur when (A.11) and the reverse of (A.7) are satisfied.

ii) Stationary screening (SS) will occur when (A.8) and (A.9) are satisfied

iii) Stationary inactivity $(\mathrm{NN})$ will occur for

$R_{G}<\min \left\{\frac{1}{\lambda \pi}, \frac{1}{\lambda \pi}((\lambda+(1-\lambda) \beta)+c), \frac{1}{\lambda \pi}((\lambda+(1-\lambda) \beta(2-\beta))+(1+(1-\lambda)(1-\beta)) c)\right\}$

Since $\frac{1}{\lambda \pi}((\lambda+(1-\lambda) \beta)+c)<\frac{1}{\lambda \pi}((\lambda+(1-\lambda) \beta(2-\beta))+(1+(1-\lambda)(1-\beta)) c)$ there is a region for small enough screening costs, i.e. $c \leq(1-\lambda)(1-\beta)$ that neither exhibits stationary screening nor inactivity. This region has the property that $R_{S S}>R_{G}$ but at the same time $R_{N S}<R_{G}$ and $R_{N S}<R_{N A}$. Hence this region specifies cyclical equilibria with a two-cycle alternating between screening and inactivity.

This completes the characterization of market equilibria. 


\section{Proof of Proposition 4.1:}

Due to the assumption of perfect recall monopolist never faces the screening externality. Hence stationarity of the pool of new projects implies stationarity of his optimization problem. His expected revenues of unscreened lending are given by $R^{A}=\lambda \pi R_{G}-1$, while the revenues of screened lending and inactivity are $R^{S}=\lambda \pi R_{G}-(\lambda+(1-\lambda) \beta)-c$ and $R^{N}=0$ respectively.

Unscreened lending (A) is viable only if $R_{G} \geq \frac{1}{\lambda \pi}$. Screened lending (S) is viable only if $R_{G} \geq \frac{\lambda+(1-\lambda) \beta+c}{\lambda \pi}$. Note that the latter condition specifies a linear function $R_{G}(c)$ in $c$.

On the other hand screened financing $(\mathrm{S})$ dominates unscreened financing (A) when the cost of screening exceed the gains from screening, i.e. when $(1-\lambda)(1-\beta) \leq c$. It turns out that screened financing is always viable at the critical level of screening costs $\bar{c}=(1-\lambda)(1-\beta)$ is $R_{G}(\bar{c})=\frac{1}{\lambda \pi}$.

Q.E.D.

\section{Proof of Proposition 5.2:}

The probability that a bad project is misclassified as a creditworthy one is $\beta$. Therefore, by Bayes' rule, the probability that a project is truly creditworthy condition on having passed the credit test is

$$
\tau=\frac{\lambda}{\lambda+(1-\lambda) \beta}
$$

Now assume that the competitive financiers randomize with respect to their screening decision. More precisely, let $\alpha$ denote the probability that a project is screened. Then the competitive lending rate, $R(\alpha)$, is determined by the condition 


$$
\alpha[\tau \pi R(\alpha)-(1+c)]+(1-\alpha)[\lambda \pi R(\alpha)-1]=0
$$

from which we can conclude that

$$
R(\alpha)=\frac{1+\alpha c}{\pi[\tau \alpha+(1-\alpha) \lambda]}
$$

It should be observed that the boundaries, i.e. the pure strategy decisions, satisfy

$$
R(0)=\frac{1}{\pi \lambda}
$$

as well as

$$
R(1)=\frac{1+c}{\pi \lambda}[\lambda+(1-\lambda) \beta] .
$$

Because $c \leq(1-\lambda)(1-\beta)$ (by Proposition 3.2 (ii)) and $\lambda+(1-\lambda) \beta<1$ it is then straightforward to verify that

$$
R(0)>R_{N S}>R(1) \text {. }
$$

This means that the allocations associated with the screening cycles in Proposition 3.2 (ii) can always be implemented as a mixed strategy equilibrium.

Q.E.D. 